\title{
Analisis Beban Kerja Mental Pada Pekerja Di Industri Pembuatan Tempe
}

\author{
Hardik Widananto $^{* 1}$, Diyah Dwi Nugraheni ${ }^{2}$ \\ 1,2Program Studi Teknik Industri, Universitas Islam Batik Surakarta, \\ Jalan Agus Salim No.10, Sondakan, Laweyan, Surakarta, 57147 \\ e-mail: ${ }^{* 1}$ hardikwidananto@gmail.com, ${ }^{2}$ diyahdn@gmail.com
}

\begin{abstract}
Abstrak
Perusahaan $\mathrm{X}$ merupakan UMKM produsen tempe, aktivitas yang diteliti dalam proses produksi tempe yaitu aktivitas pencucian kedelai, pengangkatan keranjang dan pengemasan. Tujuan dari penelitian ini yaitu mengetahui beban kerja mental pada operator yang melakukan aktivitas produksi berupa pencucian kedelai, pengangkatan keranjang dan pengemasan. Penelitian ini menggunakan metode NASA-TLX dengan indikator berupa mental demand $(\mathrm{MD})$, physical demand $(\mathrm{PD})$, temporal demand $(\mathrm{TD})$, performance $(\mathrm{P})$, effort (E), dan frustration level (FR). Hasil pengolahan data menunjukkan bahwa aktivitas pencucian kedelai memiliki skor NASA-TLX sebesar 88, aktivitas pengangkatan keranjang memiliki skor sebesar 88,67, dan aktivitas pengemasan memiliki skor sebesar 90. Hasil skor tersebut menunjukkan bahwa beban kerja pada aktivitas pencucian kedelai, pengangkatan keranjang, dan pengemasan tergolong sangat tinggi untuk operator. Dari hasil tersebut, maka perlu dilakukan perbaikan sistem kerja agar beban kerja mental operator dapat berkurang sehingga meningkatkan produktivitas dan kesehatan operator.
\end{abstract}

Kata kunci: beban kerja mental, ergonomi, NASA-TLX, UMKM

\begin{abstract}
Company $X$ is a SME company that produced tempe, activity that is examined in the production process of Tempe is soybean washing activity, basket lifting and packaging. The purpose of this research is to determine the mental workload on the operators who carried out production activities. This research used the NASA-TLX method with the indicator of mental demand $(M D)$, physical demand $(P D)$, temporal demand $(T D)$, performance $(P)$, effort $(E)$, and frustration level (FR). Data processing results show that soybean washing activity has a NASA-TLX score of 88, the basket lifting activity has a score of 88.67, and the packaging activity has a score of 90 . The score shows that the workload on soybean washing activity, basket lifting, and packaging is very high for the operator. From these results, it is necessary to repair the working system so that the operator's mental workload can decrease so as to improve the operator's productivity and health.
\end{abstract}

Keywords: mental workload, ergonomic, NASA-TLX, SME company

\section{PENDAHULUAN}

Gangguan kesehatan akibat kerja di Indonesia mengalami kenaikan dari tahun 2011 sebanyak 57.929 menjadi 97.144 pada tahun 2013 (Pusdatin, 2015). Penyebab gangguan kesehatan di tempat kerja diantaranya disebabkan adanya beban kerja yang tinggi. Beban kerja dengan intensitas yang tinggi dapat menyebabkan gangguan kesehatan serta penurunan tingkat produktivitas dari pekerja (Romadhoni, et al., 2015). Beban kerja terdiri dari beban kerja fisik dan mental (Rizqiansyah, et al., 2017). 
Beban kerja mental berbeda dengan beban kerja fisik yang dapat diamati secara langsung, oleh karena itu beban kerja mental menjadi menantang dan penting untuk diamati dibandingkan beban kerja fisik (Wulanyani, 2013).

Salah satu metode pengukuran beban kerja mental yang sering digunakan karena mudah dan lebih sensitif dalam pengukurannya adalah metode National Aeronautics and Space Administration Task Load Index (NASA-TLX) (Nofri, et al., 2017) (Akyeampopng, et al., 2014). Nasa-TLX adalah metode yang digunakan untuk melakukan analisis beban kerja mental dari pekerja di berbagai jenis pekerjaan (Afma, 2016). Metode ini dikembangkan oleh Sandra G. Hart dari NASA-Ames Research Center dan Lowell E. Staveland dari San Jose State University di tahun 1981. Metode ini terdiri dari sembilan indikator yang disederhanakan menjadi 6 indikator, yaitu Mental Demand (MD), Physical Demand (PD), Tenporal Demand (TD), Performance (P), Effort (E), dan Frustation Level (FR) (Tubbs-Cooley, et al., 2018) (Young, et al., 2008).

Beberapa penelitian tentang pengukuran beban kerja mental dengan NASATLX telah banyak diteliti, (Diniaty \& Muliyadi, 2016) melakukan analisis beban kerja fisik dan mental karyawan pada lantai produksi di PT. Pesona Laut Kuning. Penelitian ini mengukur beban kerja fisik yang diukur berdasarkan cardiovascular load (CVL) dan beban kerja mental diukur dengan metode NASA-TLX. Selain mengukur beban kerja fisik dan mental di lantai produksi, diteliti juga penyebab dari beban kerja fisik dan mental tersebut. Amri dan Herizal (2017), menganalisis beban kerja psikologis dengan menggunakan metode NASA-TLX pada operator departemen fiber line di PT. Toba Pulp Lestari. (Simanjuntak, 2010), melakukan analisis beban kerja mental pada pekerja yang bekerja di perusahaan manufaktur pembuatan tas dengan menggunakan metode NASA-TLX. Hasil penelitian menunjukkan bahwa beban kerja mental yang diterima oleh pekerja dalam kondisi tinggi, hal ini dikarenakan kurangnya perusahaan dalam memperhatikan jadwal waktu istirahat yang optimal dan kurangnya dalam perancangan dan penataan tata letak fasilitas yang ergonomis. (Wahyuniardi \& Syafe'i, 2014), melakukan analisis beban kerja pada koordinator dan manager dengan menggunakan metode NASA-TLX. Hasil pengolahan dan analisis data dapat disimpulkan bahwa rata-rata beban kerja yang dirasakan oleh manager dan koordinator berada dalam kategori over load sehingga perlu dilakukan perbaikan system kerja. Akan tetapi dari beberapa penelitian yang telah dilakukan tersebut belum terdapat penelitian tentang pengukuran beban kerja mental dengan metode NASATLX dengan obyek yang berupa UMKM. Oleh karena itu, penelitian ini bertujuan untuk mengetahui beban kerja mental yang dialami oleh operator pada UMKM produksi pembuatan tempe. Aktivitas yang diukur yaitu aktivitas pencucian, pengangkatan keranjang dan pengemasan.

\section{METODE PENELITIAN}

Pengukuran beban kerja fisik dan mental menggunakan metode NASA-Task Load Index (TLX). Terdapat 6 indikator yang digunakan dalam metode ini yaitu Mental Demand (MD), Physical Demand (PD), Temporal Demand (TD), Own Performance (OP), Effort (E), dan Frustation Level (FR). Responden yang digunakan dalam penelitian ini yaitu semua operator pada aktivitas yang diteliti. Responden mengisi kuesioner didasarkan atas apa yang mereka rasakan dalam bekerja. Penelitian ini menggunakan kuesioner NASA-TLX yang diberikan kepada operator. Kuesioner mencakup semua indikator yang telah ditentukan dalam penelitian ini. Aktivitas yang 
diteliti terdiri dari pencucian kedelai, pengangkatan keranjang dan pengemasan kedelai. Indikator NASA-TLX ditampilkan pada Tabel 16.

Tabel 16. Indikator NASA-TLX

\begin{tabular}{|c|c|c|}
\hline Skala & Rating & Keterangan \\
\hline $\begin{array}{l}\text { Mental demand } \\
\quad(M D)\end{array}$ & Rendah - Tinggi & $\begin{array}{l}\text { Seberapa besar aktivitas mental dan } \\
\text { perseptual yang dibutuhkan untuk melihat, } \\
\text { mengingat dan mencari. Apakah pekerjaan } \\
\text { tersebut sulit, sederhana atau kompleks. } \\
\text { Longgar atau ketat }\end{array}$ \\
\hline $\begin{array}{l}\text { Physical demand } \\
(P D)\end{array}$ & Rendah - Tinggi & $\begin{array}{l}\text { Jumlah aktivitas fisik yang dibutuhkan } \\
\text { (misalnya mendorong, menarik dan } \\
\text { mengontrol putaran). }\end{array}$ \\
\hline $\begin{array}{l}\text { Temporal demand } \\
\text { (TD) }\end{array}$ & Rendah - Tinggi & $\begin{array}{l}\text { Jumlah tekanan yang berkaitan dengan } \\
\text { waktu yang dirasakan selama elemen } \\
\text { pekerjaan berlangsung. Apakah pekerjaan } \\
\text { perlahan, santai, cepat, atau melelahkan }\end{array}$ \\
\hline $\begin{array}{c}\text { Own performance } \\
(O P)\end{array}$ & $\begin{array}{c}\text { Sempurna - Tidak } \\
\text { Tepat }\end{array}$ & $\begin{array}{l}\text { Seberapa besar keberhasilan seseorang di } \\
\text { dalam pekerjaannya dan seberapa puas } \\
\text { dengan hasil kerjanya }\end{array}$ \\
\hline $\begin{array}{l}\text { Frustation level } \\
\qquad(F R)\end{array}$ & Rendah - Tinggi & $\begin{array}{l}\text { Seberapa tidak aman, putus asa, } \\
\text { tersinggung, terganggu yang dirasakan }\end{array}$ \\
\hline Effort (EF) & Rendah - Tinggi & $\begin{array}{l}\text { Seberapa keras kerja yang dibutuhkan untuk } \\
\text { mencapai tingkat performansi. }\end{array}$ \\
\hline
\end{tabular}

Hancock dan Meshkkati (1988) menjelaskan langkah-langkah pengukuran dengan metode NASA-TLX.

1. Pembobotan

Pada proses pembobotan, responden diminta untuk mengisi kuesioner sesuai dengan keadaan yang dialami saat melakukan aktivitas/pekerjaan. Pengukuran pembobotan menggunakan matriks tabel perbandingan berpasangan seperti ditampilkan pada Gambar 6. Dari matriks tersebut maka dilakukan perhitungan terhadap jumlah indikator yang diisi oleh operator. Jumlah indikator tersebut menjadi bobot untuk tiap indikator beban mental.

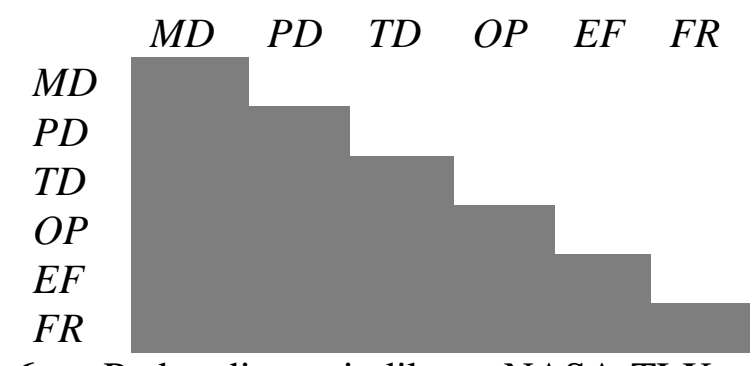

Gambar 6. Perbandingan indikator NASA-TLX 
2. Pemberian Rating

Pemberian rating dilakukan oleh operator dengan tujuan untuk mengetahui skor beban mental yang dirasakan oleh operator. Skor beban mental berada pada range 0-100 dimana pengisian didasarkan atas apa yang dirasakan oleh operator ketika melakukan pekerjaan. Skor 0 menunjukkan bahwa pekerjaan memiliki rating yang rendah sedangkan skor 100 memiliki rating yang tinggi. Rating rendah mengindikasikan bahwa pekerjaan tidak memerlukan usaha dan rating tinggi mengindikasikan bahwa pekerjaan memerlukan usaha yang maksimal. Untuk mendapatkan skor beban mental NASA-TLX, bobot yang diperoleh pada perhitungan bobot dikalikan dengan rating untuk setiap indikator kemudian dijumlahkan dan dibagi dengan 15 (jumlah perbandingan berpasangan). Skala rating NASA-TLX ditunjukkan pada Gambar 7.

Mental Demand (Seberapa besar tuntutan mental dalam pelaksanaan tugas?)

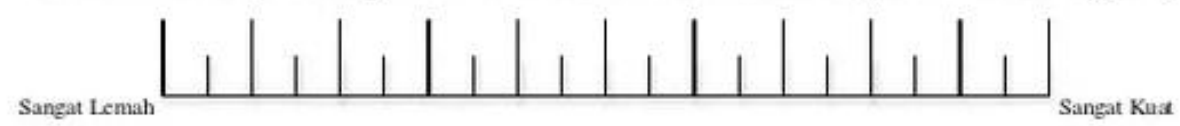

Physical Demand (Seberapa besar tuntutan fisik dalam pelaksanaan tugas?)

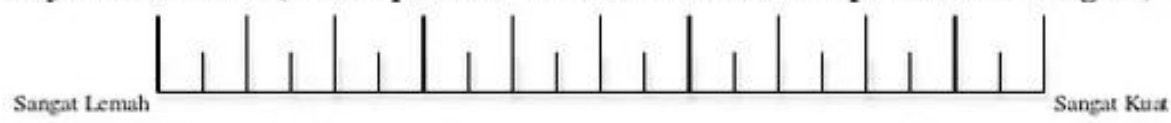

Temporal Demand (Seberapa besar perasaan tergesa-gesa dalam penyelesaian tugas?)

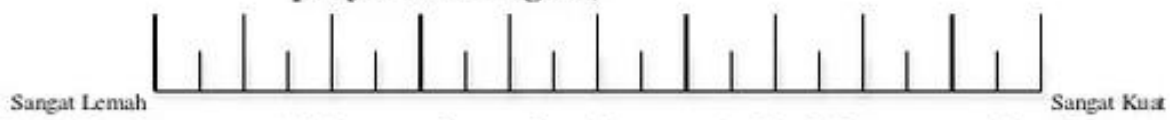

Own Performance (Seberapa besar kesuksesan Anda dalam menyelesaikan tugas yang telah diperintahkan kepada Anda?)

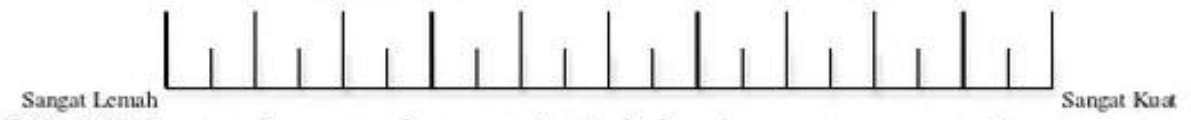

Effort (Seberapa besar usaha yang Anda keluarkan agar mencapai tingkatan performa kerja saat ini?)

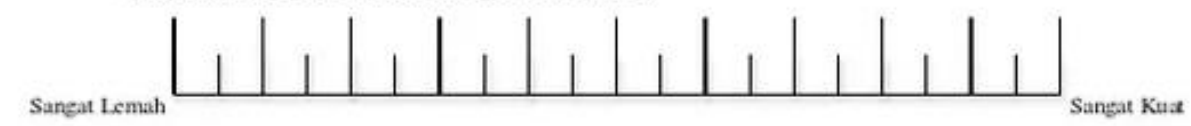

Frustration (Seberapa besar rasa tidak aman, terganggu, stres, terluka, dan berkecil hati saat mengerjakan tugas?)

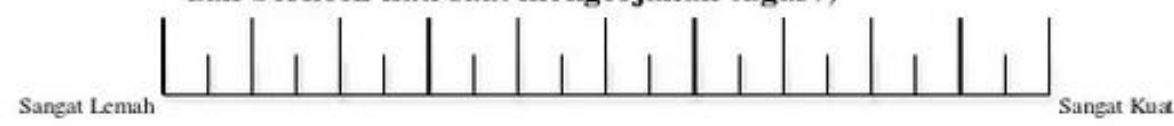

Gambar 7. Rating NASA-TLX

3. Menghitung nilai produk

Nilai produk dihitung dengan mengalikan rating dengan bobot faktor untuk masing-masing indikator, sehingga dihasilkan 6 nilai produk untuk 6 indikator (MD, PD, TD, OP, EF, dan FR).

4. Menghitung Weighted Workload (WWL)

WWL diperoleh dengan menjumlahkan keenam nilai produk.

5. Menghitung rata-rata WWL

Rata-rata WWL dihitung dengan membagi WWL dengan jumlah bobot total.

6. Intepretasi Skor

Intepretasi skor bertujuan untuk menentukan golongan beban kerja. Golongan beban kerja yang diperoleh terbagi ke dalam lima tingkat sebagaimana Tabel 17. 
Tabel 17. Skor NASA-TLX

\begin{tabular}{lc}
\hline \multicolumn{1}{c}{$\begin{array}{c}\text { Golongan } \\
\text { Beban Kerja }\end{array}$} & \multicolumn{1}{c}{ Nilai } \\
\hline Rendah & $0-9$ \\
\hline Sedang & $10-29$ \\
\hline Agak Tinggi & $30-49$ \\
\hline Tinggi & $50-79$ \\
\hline Sangat Tinggi & $80-100$ \\
\hline
\end{tabular}

\section{HASIL DAN PEMBAHASAN}

\subsection{Pembobotan}

Tabel 18.

Pembobotan hasil kuesioner yang telah diisi oleh operator ditampilkan pada

Tabel 18. Data pembobotan kuesioner

\begin{tabular}{lccccccc}
\hline \multirow{2}{*}{ Aktivitas Operator } & \multicolumn{7}{c}{ Indikator } \\
\cline { 2 - 8 } & MD & PD & TD & OP & EF & FR & Total \\
\hline Pencucian kedelai & 5 & 3 & 1 & 4 & 2 & 0 & 15 \\
\hline Pengangkatan keranjang & 4 & 2 & 1 & 5 & 3 & 0 & 15 \\
\hline Pengemasan & 4 & 2 & 1 & 3 & 5 & 0 & 15 \\
\hline
\end{tabular}

\subsection{Pemberian Rating}

Pemberian rating pada kuesioner NASA-TLX dilakukan oleh operator yang melakukan aktivitas pekerjaannya. Pemberian rating ini bersifat subjektif karena didasarkan atas apa yang mereka alami, rasakan dan kerjakan terhadap masing-masing aktivitas pekerjaannya. Hasil rating ditampilkan pada Tabel 19.

Tabel 19. Hasil rating

\begin{tabular}{lcccccc}
\hline \multirow{2}{*}{ Aktivitas Operator } & \multicolumn{7}{c}{ Indikator } \\
\cline { 2 - 7 } & MD & PD & TD & OP & EF & FR \\
\hline Pencucian kedelai & 80 & 90 & 50 & 100 & 100 & 0 \\
\hline Pengangkatan keranjang & 90 & 80 & 60 & 90 & 100 & 0 \\
\hline Pengemasan & 95 & 65 & 40 & 100 & 100 & 5 \\
\hline
\end{tabular}

\subsection{Nilai Produk}

Nilai produk diperoleh dengan mengalikan rating dengan bobot faktor. Hasil nilai produk disajikan pada Tabel 20.

Tabel 20. Total nilai produk

\begin{tabular}{lcccccc}
\hline \multirow{2}{*}{ Aktivitas Operator } & \multicolumn{7}{c}{ Indikator } \\
\cline { 2 - 7 } & MD & PD & TD & OP & EF & FR \\
\hline Pencucian kedelai & 400 & 270 & 50 & 400 & 200 & 0 \\
\hline Pengangkatan keranjang & 360 & 160 & 60 & 450 & 300 & 0 \\
\hline Pengemasan & 380 & 130 & 40 & 300 & 500 & 0 \\
\hline
\end{tabular}




\subsection{Weighted Workload (WWL)}

Hasil weighted workload dapat dilihat pada Tabel 21.

Tabel 21. Total nilai Weighted Workload

\begin{tabular}{lccccccc}
\hline \multirow{2}{*}{ Aktivitas Operator } & \multicolumn{7}{c}{ Indikator } \\
\cline { 2 - 7 } & MD & PD & TD & OP & EF & FR & Total \\
\hline Pencucian kedelai & 400 & 270 & 50 & 400 & 200 & 0 & 1320 \\
\hline Pengangkatan keranjang & 360 & 160 & 60 & 450 & 300 & 0 & 1330 \\
\hline Pengemasan & 380 & 130 & 40 & 300 & 500 & 0 & 1350 \\
\hline
\end{tabular}

\subsection{Rata-rata Weighted Workload (WWL)}

Rata-rata WWL diperoleh dengan membagi WWL dengan jumlah bobot total, hasilnya dapat dilihat pada Tabel 22.

Tabel 22. Perhitungan rata-rata Weighted Workload

\begin{tabular}{|c|c|c|c|c|c|c|c|}
\hline \multirow{2}{*}{ Aktivitas Operator } & \multicolumn{6}{|c|}{ Indikator } & \multirow{2}{*}{ Total } \\
\hline & MD & PD & TD & OP & EF & FR & \\
\hline Pencucian kedelai & 26,67 & 18 & 3,33 & 26,67 & 13,33 & 0 & 88 \\
\hline Pengangkatan keranjang & 24 & 10,67 & 4 & 30 & 20 & 0 & 88,67 \\
\hline Pengemasan & 25,33 & 8,67 & 2,67 & 20 & 33,33 & 0 & 90 \\
\hline
\end{tabular}

\subsection{Intepretasi Skor NASA-TLX}

Intepretasi skor NASA-TLX pada penelitian ini dapat dilihat pada Tabel 23.

Tabel 23. Kategori penilaian beban kerja

\begin{tabular}{lcc}
\hline \multicolumn{1}{c}{ Aktivitas Operator } & Nilai Beban Kerja & Kategori \\
\hline Pencucian kedelai & 88 & Sangat Tinggi \\
Pengangkatan keranjang & 88,67 & Sangat Tinggi \\
Pengemasan & 90 & Sangat Tinggi \\
\hline
\end{tabular}

Berdasarkan perhitungan beban kerja yang telah dilakukan dengan menggunakan metode NASA-TLX, beban kerja mental yang dialami oleh operator yang melakukan aktivitas pencucian kedelai sebesar 88. Dari nilai tersebut dapat dipastikan bahwa aktivitas pencucian kedelai termasuk dalam kategori sangat tinggi. Skor NASA-TLX untuk aktivitas pengangkatan keranjang sebesar 88,67, nilai ini menunjukkan bahwa aktivitas tersebut termasuk dalam kategori sangat tinggi. Aktivitas pengemasan memiliki skor sebesar 90, nilai ini menunjukkan bahwa aktivitas tersebut termasuk dalam kategori sangat tinggi.

\section{KESIMPULAN}

Berdasarkan hasil penelitian dan pembahasan diperoleh bahwa beban kerja mental operator pada aktivitas pencucian kedelai, pengangkatan keranjang, dan pengemasan semuanya masuk dalam kategori sangat tinggi. Nilai beban kerja mental paling tinggi terdapat pada aktivitas pengemasan. Dari hasil tersebut, maka perlu dilakukan perbaikan sistem kerja agar beban kerja mental operator dapat berkurang sehingga meningkatkan produktivitas dan kesehatan operator. 


\section{DAFTAR PUSTAKA}

Afma, V. M., 2016, Analisa Beban Kerja Operator Inspeksi Dengan Metode NASATLX (Task Load Index) Di PT. XYZ, Profisiensi, vol. 4, no. 2, 118-122.

Akyeampopng, J., Udoka, S., Caruso, G. \& Bordegoni, M., 2014, Evaluation of Hydraulic Excavator Human-Machine Interface Concepts Using NASA TLX, Intenational Journal of Industrial Ergonomics, vol. 44, 374-382.

Amri \& Herizal, 2017, Analisis Beban Kerja Psikologis dengan Menggunakan Metode NASA-TLX pada Operator Departemen Fiber Line di PT. Toba Pulp Lestari, Industrial Engineering Journal, vol. 6, no. 1, 29-35.

Diniaty, D. \& Muliyadi, Z., 2016, Analisis Beban Kerja Fisik dan Mental Karyawan pada Lantai Produksi di PT. Pesona Laut Kuning, Jurnal Sains, Teknologi dan Industri, vol. 13, no. 2, 203-210.

Hancock, P. A. \& Meshkati, N., 1988, Human Mental Workload, Elsevier.

Nofri, T., Prastawa, H. \& Susanto, N., 2017, Pengukuran Beban Mental di Kalangan Mahasiswa Menggukan Metode NASA-TLX (Studi Kasus: Mahasiswa Departemen Teknik Industri UNDIP).

Pusdatin, 2015, Situasi Kesehatan Kerja, Pusat Data dan Informasi Kementrian Kesehatan RI.

Rizqiansyah, M. Z. A., Hanurawan, F. \& Setiyowati, N., 2017, Hubungan Antara Beban Kerja Fisik dan Beban Kerja Mental Berbasis Ergonomi Terhadap Tingkat Kejenuhan Kerja Pada Karyawan PT. Jasa Marga (Persero) Tbk Cabang Surabaya Gempol, Jurnal Sains Psikologi, vol. 6, no. 1, 37-42.

Romadhoni, L. C., Asmony, T. \& Suryatni, M., 2015, Pengaruh Beban Kerja, Lingkungan Kerja, dan Dukungan Sosial Terhadap Burnout Pustakawan Di Kota Mataram, Jurnal Ilmu Perpustakaan, Informasi dan Kearsipan Khizanah Al-Hikmah, vol. 3, no. 2, 125-145.

Simanjuntak, R. A., 2010, Analisis Beban Kerja Mental dengan Metoda NASA-Task Load Index, Jurnal Teknologi Technoscientia, vol. 3, no. 1.

Tubbs-Cooley, H. L., Mara, C. A., Carle, A. C. \& Gurses, A. P., 2018, The NASA Task Load Index as a Measure of Overall Workload Among Neonatal, Paediatric and Adult Intensive Care Nurses, Intensive \& Critical Care Nursing.

Wahyuniardi, R. \& Syafe'i, Y., 2014, Analisis Beban Kerja Koordinator dan Manager menggunakan Metode NASA-TLX, Seminar Nasional IENACO.

Wulanyani, N. M. S., 2013, Tantangan dalam Mengungkap Beban Kerja Mental, Buletin Psikologi, vol. 21, no. 2, 80-89.

Young, G., Zavelina, L. \& Hooper, V., 2008. Assessment of Workload Using NASA Task Load Index in Perianesthesia Nursing. Journal of PeriAnesthesia Nursing, 23(2), pp. 102-110. 
